\title{
Effect of Meals with Milk on Body Iron Stores and Improvement of Dietary Habit during Weight Loss in Female Rhythmic Gymnasts
}

\author{
Yukari KAWANO $^{1, *}$, Sakuko ISHIZAKI ${ }^{1}$, Shigeko SASAMOTO ${ }^{1}$, Youko KATOH $^{1}$ and Shuhei KoBAYASHI ${ }^{2}$ \\ ${ }^{1}$ Department of Exercise Sciences, Japan Women's College of Physical Education, \\ Kita-karasuyama 8-19-1, Setagaya-ku, Tokyo 157-8565, Japan \\ ${ }^{2}$ Department of Health and Nutrition, Wayo Women's College, Chiba 272-8533 Japan
}

(Received May 9, 2002)

\begin{abstract}
Summary This study investigated the effect of different timings of milk intake on body iron stores and improvement in the dietary habit of female collegiate rhythmic gymnasts. Subjects took iron tablets at both breakfast and dinner times during a weight-loss period. In addition, subjects ingested low-fat milk twice a day either at breakfast or dinner (group I; $n=7$ ), or between meals (group II; $n=6$ ) for 3 mo. Blood was collected four times. Red blood cell count, hemoglobin, serum iron, ferritin and erythropoietin concentrations were measured. Subjects completed a dietary survey for three consecutive days before each blood sampling. The mean body fat in both groups I and II was significantly lower after 3 mo than at the start of the study $(p<0.01)$. Red blood cell count and hemoglobin of group I were significantly higher as compared to those of group II $(p<0.05)$. Serum iron concentrations and transferrin saturation values remained unchanged in both groups. Serum ferritin concentrations in group I were significantly higher 3 mo after the start of the study, but this was not observed in group II. Energy and carbohydrate intake in group II, but not in group I, were significantly lower after 3 mo as compared to those after 1 and 2 mo as a result of missing meals. In conclusion, iron-supplemented meals via milk ingestion did not decrease body iron stores and maintained higher body iron stores compared to a diet that included milk intake between meals. Further, milk intake with meals is related to keeping regular meal times and frequency.
\end{abstract}

Key Words different timing of milk intake, body iron stores, weight loss, female athletes

It is well known that phytate, tannin and some types of dietary fiber inhibit iron absorption in the small intestine $(1,2)$. Ascorbic acid is an enhancer of iron absorption in adults (3), infants and children (4-6). However, the precise mechanism of iron absorption connected to the development of iron-deficient anemia in humans is unknown. In addition, the effects of intensity and duration of exercise on the absorption of different iron compounds remains to be determined.

Rhythmic gymnastics is one of the most stressful sports. Many athletes involved in rhythmic gymnastics lose weight to improve performance. Most athletes therefore repeat weight gain/loss cycles several times. Nutritional surveys have shown suboptimal calcium, iron and zinc intake in elite rhythmic gymnastics (7).

Losing weight can be accompanied by an imbalance in energy intake and expenditure. A positive correlation between dietary energy intake and the intake of essential nutrients including protein, carbohydrates and iron is well accepted. It appears, therefore, that iron intake may possibly decrease during a period of weight loss. Losing weight through inadequate dietary intake has been reported to result in nutritional problems including eating disorders, iron-deficient anemia, protein-energy malnutrition, anorexia, bone fractures and osteo-

*E-mail: kawano@jwcpe.ac.jp porosis $(8-10)$.

Iron deficiency is often associated with impaired endurance work capacity in humans and rats (11), and iron supplements may be useful in treating and preventing athletes from iron-deficient anemia (12). On the other hand, low calcium (Ca) intake increases the risk of osteoporosis (13). Calcium was the only nutrient measured in the National Nutrition Survey for Japanese that did not meet the Recommended Dietary Allowance in Japan (14). Milk is one of the most convenient sources of calcium and protein. Combining hamburger with milk at meals has been reported to inhibit nonheme iron absorption (15), while other studies have not shown an effect of calcium on iron absorption (16). Most studies have examined the effect of milk intake on intestinal iron absorption in the short term, however, little has been reported on the effect of long-term intake of milk on intestinal iron absorption.

This study was designed to determine if milk intake during a meal decreases body iron stores in female athletic students during a three-month weight-loss program, and to examine the effect of milk intake during a meal in terms of improving their nutritional status.

\section{SUBJECTS AND METHODS}

Subjects. Thirteen female collegiate rhythmic gymnastic athletes were voluntarily recruited. The average 
age was 19.3 $\pm 1.4 \mathrm{yr}(18-21 \mathrm{yr})$, and they had been involved in the sport for $9.0 \pm 2.9 \mathrm{yr}(4-15 \mathrm{yr})$. The team won second place in the Inter College of Athletic Meet held in Japan on August 4, 1998. Intervention ended $1 \mathrm{~d}$ after the meet, and their last blood samplings were taken on that day. All subjects were healthy and none of them had anemia or was diagnosed as having a blood $\mathrm{Hb}$ concentration lower than $12 \mathrm{~g} / \mathrm{dL}$ at the start of this study. All subjects were normotensive non-smokers.

The research program was reviewed and approved by the Ethics Committees of Japan Women's College of Physical Education (No. 98-1). Each subject provided written informed consent in accordance with procedures approved by the Committee. Subjects were given the results of all measurements as a benefit of participation.

Experimental design. Based on preliminary baseline blood testing, the subjects were randomly assigned to either a group in which milk was ingested during breakfast and dinner (group I, $n=7$ ), or a group in which the subjects ingested milk twice between meals (group II, $n=6$ ). All subjects took non-heme iron tablets with meals twice a day, at breakfast and dinner. The iron supplement contained $4 \mathrm{mg}$ iron as iron pyrophosphate (Zavas Fe TAB; Meiji Seika Co., Ltd., Japan). Each $250 \mathrm{~mL}$ of low-fat milk contained $9.5 \mathrm{~g}$ protein, $2.5 \mathrm{~g}$ fat and $325 \mathrm{mg}$ calcium (Snow Brand Milk Products Co., Ltd., Japan). The dietary manipulation lasted for $3 \mathrm{mo}$. No restrictions on food or physical activities were placed on the subjects throughout the study.

Dietary analysis. A trained dietitian using the 24-h recall method determined the food intake for three consecutive days prior to each blood sampling. The intake of individual nutrients was calculated using the Standard Tables of Food Composition for Japanese, 4th Edition (17).

Hematological analysis. Blood samples were obtained four times during this study (before and at the end of first, second and third months of the intervention period) by venipuncture from an antecubital vein in the morning (08:00-09:00) after overnight fasting.

Blood samples were collected in EDTA-2K tubes. Hematological parameters, including RBC count, $\mathrm{Hb}$, hematocrit $(\mathrm{Ht})$, platelets, mean corpuscular volume $(\mathrm{MCV})$, mean corpuscular hemoglobin $(\mathrm{MCH})$ and mean corpuscular hemoglobin concentration $(\mathrm{MCHC})$, were obtained using a Coulter CBC5 analyzer (Remed, Poland). Reticulocyte count, serum iron, ferritin, total iron binding capacity (TIBC), erythropoietin (EPO) and haptoglobin (hp) were measured by Medical Laboratory, Co., Ltd. (Tokyo, Japan).

Statistics. All values in the tables and figures are expressed as mean \pm standard deviation (SD). Statistical significance was determined with ANOVA by post-hoc Tukey tests. Paired $t$-test was used to assess any significant differences. The accepted level of significance was $p<0.05$.

\section{Characteristics of the subjects \\ A study investigator usually contacted the partici- pants every day, which helped to prevent any mistake in milk or iron-supplement intake. No surplus of tablets was registered during the study for any of the partici- pants.}

Subjects experienced slight weight loss from the baseline throughout the 3-mo intervention, but it was not significant. The mean height and body weight were significantly lower in group II than in group I $(p<0.01)$ during the study (Table 1). Although BMI values were unchanged throughout the study, mean body fat in both groups I and II was significantly lower after $3 \mathrm{mo}$ of intervention than that measured as the baseline $(p<0.01)$.

\section{Hematological changes}

$\mathrm{RBC}$ count, $\mathrm{Hb}$ and $\mathrm{Ht}$ values were significantly higher in group I as compared to those of group II during the study ( $p<0.05$; Table 2$)$. Mean values of MCV, $\mathrm{MCH}, \mathrm{MCHC}$, reticulocytes and $\mathrm{EPO}$ in both groups were relatively constant during the study. Body iron stores suggested by the serum iron concentrations, TIBC, unsaturated iron binding capacity (UIBC) and transferrin saturation in both groups remained unchanged throughout the study. (Table 2). However, serum ferritin concentrations increased significantly in group I after 3 mo as compared to that measured as the

Table 1. Characteristics of the subjects.

\begin{tabular}{|c|c|c|c|c|c|c|}
\hline Periods & Group & Baseline & 1 mo after & 2 mo after & 3 mo after & ANOVA \\
\hline \multirow[t]{2}{*}{ Height $(\mathrm{cm})$} & I & $162 \pm 5.4^{\#}$ & & & & \\
\hline & II & $158 \pm 1.2$ & & & & \\
\hline \multirow{2}{*}{ Body weight $(\mathrm{kg})$} & I & $50.9 \pm 1.8$ & $50.1 \pm 1.6$ & $50.8 \pm 1.7$ & $49.4 \pm 1.8$ & group $(p<0.01)$ \\
\hline & II & $45.9 \pm 1.0$ & $46.9 \pm 0.9$ & $47.2 \pm 1.0$ & $44.6 \pm 0.9$ & \\
\hline \multirow[t]{2}{*}{ BMI } & I & $19.3 \pm 0.5$ & $19.0 \pm 0.5$ & $19.1 \pm 0.4$ & $18.8 \pm 0.5$ & $\mathrm{~ns}$ \\
\hline & II & $18.3 \pm 0.3$ & $18.2 \pm 0.3$ & $18.3 \pm 0.2$ & $17.8 \pm 0.1$ & \\
\hline \multirow[t]{2}{*}{ Body fat (\%) } & I & $23.0 \pm 1.1^{\mathrm{a}}$ & $22.1 \pm 1.3$ & $22.0 \pm 1.2$ & $21.7 \pm 1.1^{\mathrm{a}}$ & \\
\hline & II & $22.0 \pm 0.4^{\mathrm{a}}$ & $21.0 \pm 0.5$ & $21.3 \pm 0.4$ & $20.2 \pm 0.5^{\mathrm{a}}$ & \\
\hline
\end{tabular}

I, simultaneous intake with milk during a meal; II, intake of milk between meals.

\# Significantly different from the corresponding value of II group $(p<0.01)$.

${ }^{a}$ Statistical difference was observed between the same initials within the same group $(p<0.01)$. ns: No significant difference was observed between the groups or the times by ANOVA. 
Table 2. Changes in hematological parameters during the experiment.

\begin{tabular}{|c|c|c|c|c|c|c|}
\hline Periods & Group & Baseline & 1 mo after & 2 mo after & 3 mo after & ANOVA \\
\hline \multirow[t]{2}{*}{$\mathrm{RBC}$} & I & $424 \pm 13$ & $419 \pm 18$ & $422 \pm 17$ & $435 \pm 15$ & \multirow[t]{2}{*}{ group $(p<0.05)$} \\
\hline & II & $425 \pm 21$ & $406 \pm 22$ & $404 \pm 18$ & $410 \pm 33$ & \\
\hline \multirow{2}{*}{$\mathrm{Hb}$} & I & $12.9 \pm 0.1$ & $12.8 \pm 0.2$ & $13.1 \pm 0.2$ & $13.4 \pm 0.2$ & \multirow[t]{2}{*}{ group $(p<0.001)$} \\
\hline & II & $12.7 \pm 0.2$ & $12.2 \pm 0.1$ & $12.3 \pm 0.2$ & $12.6 \pm 0.4$ & \\
\hline \multirow[t]{2}{*}{$\mathrm{Ht}$} & I & $37.9 \pm 0.4$ & $38.0 \pm 0.7$ & $38.3 \pm 0.7$ & $39.4 \pm 0.6$ & \multirow[t]{2}{*}{ group $(p<0.001)$} \\
\hline & II & $37.5 \pm 0.7$ & $36.0 \pm 0.5$ & $36.2 \pm 0.5$ & $37.0 \pm 1.3$ & \\
\hline \multirow[t]{2}{*}{ Platelet } & I & $27.2 \pm 1.0$ & $24.7 \pm 0.4$ & $26.4 \pm 0.4$ & $28.4 \pm 0.4$ & \multirow[t]{2}{*}{ group $(p<0.05)$} \\
\hline & II & $24.3 \pm 1.2$ & $22.9 \pm 0.5$ & $21.9 \pm 0.4$ & $22.9 \pm 0.7$ & \\
\hline \multirow[t]{2}{*}{$\mathrm{MCV}$} & I & $90.0 \pm 1.1$ & $90.9 \pm 0.9$ & $91.1 \pm 0.8$ & $90.9 \pm 0.9$ & \multirow[t]{2}{*}{ ns } \\
\hline & II & $88.3 \pm 1.7$ & $89.0 \pm 2.0$ & $89.8 \pm 1.9$ & $90.0 \pm 1.8$ & \\
\hline \multirow[t]{2}{*}{$\mathrm{MCH}$} & I & $30.3 \pm 0.4$ & $30.7 \pm 0.4$ & $31.3 \pm 0.4$ & $30.7 \pm 0.3$ & \multirow[t]{2}{*}{ ns } \\
\hline & II & $29.8 \pm 0.8$ & $30.0 \pm 0.6$ & $30.7 \pm 0.8$ & $30.5 \pm 0.6$ & \\
\hline \multirow[t]{2}{*}{$\mathrm{MCHC}$} & $\mathrm{I}$ & $33.9 \pm 0.2$ & $33.9 \pm 0.2$ & $34.4 \pm 0.3$ & $34.0 \pm 0.2$ & \multirow[t]{2}{*}{ ns } \\
\hline & II & $33.8 \pm 0.2$ & $33.8 \pm 0.3$ & $34.2 \pm 0.2$ & $34.5 \pm 0.5$ & \\
\hline \multirow{2}{*}{$\begin{array}{l}\text { Reticurocytes } \\
(\%)\end{array}$} & I & $7.6 \pm 1.3$ & $7.3 \pm 1.1$ & $7.1 \pm 1.0$ & $6.3 \pm 1.0$ & \multirow[t]{2}{*}{ ns } \\
\hline & II & $9.8 \pm 2.3$ & $8.5 \pm 2.2$ & $7.2 \pm 1.8$ & $6.3 \pm 1.5$ & \\
\hline \multirow[t]{2}{*}{ Erythropoietin } & $\mathrm{I}$ & $8.2 \pm 1.8$ & $7.2 \pm 1.5$ & $7.1 \pm 0.9$ & $7.2 \pm 1.4$ & \multirow[t]{2}{*}{ ns } \\
\hline & II & $6.7 \pm 1.2$ & $7.0 \pm 1.1$ & $7.6 \pm 0.6$ & $9.9 \pm 4.6$ & \\
\hline \multirow{2}{*}{$\begin{array}{l}\text { Serum iron } \\
(\mu \mathrm{g} / \mathrm{dL})\end{array}$} & I & $109 \pm 16$ & $100 \pm 9$ & $112 \pm 19$ & $116 \pm 19$ & \multirow[t]{2}{*}{ ns } \\
\hline & II & $95 \pm 20$ & $111 \pm 24$ & $84 \pm 12$ & $85 \pm 24$ & \\
\hline \multirow{2}{*}{$\begin{array}{l}\mathrm{TIBC} \\
(\mu \mathrm{g} / \mathrm{dL})\end{array}$} & I & $445 \pm 27$ & $505 \pm 44$ & $457 \pm 37$ & $441 \pm 39$ & \multirow[t]{2}{*}{ ns } \\
\hline & II & $442 \pm 27$ & $484 \pm 29$ & $443 \pm 18$ & $443 \pm 18$ & \\
\hline \multirow{2}{*}{$\begin{array}{l}\mathrm{UIBC} \\
(\mu \mathrm{g} / \mathrm{dL})\end{array}$} & I & $336 \pm 32$ & $405 \pm 48$ & $346 \pm 28$ & $325 \pm 37$ & \multirow[t]{2}{*}{ ns } \\
\hline & II & $347 \pm 39$ & $373 \pm 37$ & $359 \pm 23$ & $358 \pm 24$ & \\
\hline \multirow[t]{2}{*}{$\operatorname{Tf}(\%)$} & I & $24.9 \pm 3.9$ & $20.6 \pm 2.5$ & $24.2 \pm 3.2$ & $26.8 \pm 4.5$ & \multirow[t]{4}{*}{ ns } \\
\hline & II & $22.2 \pm 4.9$ & $23.1 \pm 4.7$ & $19.1 \pm 2.8$ & $18.9 \pm 5.2$ & \\
\hline \multirow{2}{*}{$\begin{array}{l}\text { Ferritin } \\
(\mathrm{ng} / \mathrm{mL})\end{array}$} & I & $36.0 \pm 7.8^{\mathrm{a}}$ & $28.1 \pm 9.2$ & $35.7 \pm 8.9$ & $57.4 \pm 12.6^{\mathrm{a}}$ & \\
\hline & II & $41.3 \pm 13.9$ & $34.8 \pm 10.2$ & $36.5 \pm 10.0$ & $36.5 \pm 10.7$ & \\
\hline
\end{tabular}

I, simultaneous intake with milk during a meal; II, intake of milk between meals.

$\mathrm{RBC}$, red blood cells; Hb, hemoglobin; Ht, hematocrit; $\mathrm{MCV}$, mean corposcular volume; $\mathrm{MCH}$, mean corposcular hemoglobin; MCHC, mean corposcular hemoglobin concentration; TIBC, total iron-binding capacity; UIBC, unsaturated iron-binding capacity; Tf, saturated transferrin; ns, no significant difference. Group, significantly different between two groups. Values are expressed as mean \pm SD.

${ }^{a}$ Statistical difference was observed between the same initials within the same group $(p<0.05)$. ns: No significant difference was observed between the groups or the times by ANOVA.

baseline $(p<0.05)$. This was not observed in group II. The mean EPO concentrations in groups I and II did not change throughout the study, and were $8.2 \pm 1.8$ and $6.7 \pm 1.2$ at baseline, and $7.2 \pm 1.4$ and $9.9 \pm 4.6$ at three months, respectively.

\section{Daily intakes and corresponding values}

Mean daily energy, protein, fat, and carbohydrate intakes in group I remained unchanged throughout the experimental period (Table 3). Although no restrictions on food and no guidance on dietary habits were placed on the subjects throughout the study, an improvement of dietary habit such as maintaining regular meal times and frequency (three meals a day) was observed in group I during the study, whereas skipping meals was observed among subjects of group II at 3 mo. The ratios of energy intakes derived from breakfast, lunch and dinner were $1: 0.96: 1.33$ in group I and $1: 1.58: 1.54$ in group II at 3 mo. Mean daily intakes of energy and carbohydrate in group II were significantly lower at 3 mo compared to the values at 1 and 2 mo. Protein intakes were unchanged throughout the study. The ratios of animal protein intake to total protein intake at 3 mo were $68.4 \pm 8.8 \%$ and $56.6 \pm 9.3 \%$ in groups I and II, respectively. Dietary fiber intakes in both groups were significantly lower at 3 mo than at 2 mo. Calcium intakes derived from milk were the same in both groups and increased gradually at 1,2 and 3 mo as compared to those at baseline. There were no significant changes in vitamin $C$ intake in either group during the experimental period (Table 3).

The daily intake of calcium and iron was higher during the experimental period as compared to that measured at baseline. The daily ratio of calcium-to-iron intake decreased significantly in both groups, from baseline throughout $3 \mathrm{mo}$ (Table 3). The mean daily ratio of vitamin C-to-iron intake tended to decrease in both groups after the start of the study, and was significantly lower in group II. The daily mean ratio of vitamin C-toiron intake during the study period was relatively lower in group II as compared to the corresponding values of group I.

\section{DISCUSSION}

The present study indicates that the oral intake of 
Table 3. Comparison of nutrient intakes between the groups.

\begin{tabular}{|c|c|c|c|c|c|c|}
\hline Periods & Group & Baseline & 1 mo after & 2 mo after & 3 mo after & ANOVA \\
\hline Energy & I & $1,589 \pm 180$ & $1,568 \pm 180$ & $1,640 \pm 173$ & $1,499 \pm 199$ & \\
\hline$(\mathrm{kcal} / \mathrm{d})$ & II & $1,599 \pm 129$ & $1,788 \pm 121^{\mathrm{a}}$ & $1,780 \pm 111^{\mathrm{b}}$ & $1,434 \pm 73^{\mathrm{a}, \mathrm{b}}$ & ${ }^{\mathrm{a}, \mathrm{b}} p<0.05$ \\
\hline Protein & I & $50.9 \pm 6.7$ & $50.1 \pm 6.3$ & $46.2 \pm 5.5$ & $49.1 \pm 6.3$ & ns \\
\hline$(\mathrm{g} / \mathrm{d})$ & II & $52.8 \pm 5.0$ & $55.9 \pm 3.0$ & $59.2 \pm 4.1$ & $54.8 \pm 5.2$ & \\
\hline Fat & I & $52.7 \pm 9.3$ & $53.0 \pm 9.6$ & $57.0 \pm 10.4$ & $49.8 \pm 10.9$ & ns \\
\hline$(\mathrm{g} / \mathrm{d})$ & II & $54.9 \pm 13.6$ & $59.0 \pm 11.2$ & $61.5 \pm 10.8$ & $50.1 \pm 7.6$ & \\
\hline Carbohydrate & I & $234 \pm 47$ & $222 \pm 35$ & $234 \pm 37$ & $209 \pm 34$ & \\
\hline$(\mathrm{g} / \mathrm{d})$ & II & $216 \pm 39$ & $254 \pm 33^{b}$ & $238 \pm 19^{a}$ & $185 \pm 26^{a, b}$ & ${ }^{\mathrm{a}} p<0.05,{ }^{\mathrm{b}} p<0.01$ \\
\hline Dietary fiber & I & $5.8 \pm 1.3$ & $6.4 \pm 1.6$ & $8.4 \pm 2.6^{\mathrm{a}}$ & $5.1 \pm 1.7^{\mathrm{a}}$ & ${ }^{\mathrm{a}} p<0.05$ \\
\hline$(\mathrm{g} / \mathrm{d})$ & II & $6.8 \pm 1.1^{\mathrm{a}}$ & $7.3 \pm 1.9$ & $9.4 \pm 1.5^{\mathrm{a}, \mathrm{c}}$ & $5.3 \pm 1.2^{\mathrm{c}}$ & ${ }^{\mathrm{a}} p<0.05,{ }^{\mathrm{c}} p<0.001$ \\
\hline Calcium & I & $514 \pm 139^{a}$ & $698 \pm 103$ & $706 \pm 48$ & $861 \pm 74^{\mathrm{a}}$ & ${ }^{\mathrm{a}} p<0.05$ \\
\hline$(\mathrm{mg} / \mathrm{d})$ & II & $514 \pm 64^{a, b}$ & $841 \pm 107^{\mathrm{a}}$ & $720 \pm 97$ & $804 \pm 95^{b}$ & a,b $p<0.05$ \\
\hline Iron & $\mathrm{I}$ & $5.5 \pm 0.6$ & $12.0 \pm 2.5$ & $15.8 \pm 0.8$ & $16.3 \pm 0.8^{\#}$ & \# baseline : others $p<0.001$ \\
\hline$(\mathrm{mg} / \mathrm{d})$ & II & $6.1 \pm 0.5$ & $16.1 \pm 1.5$ & $18.0 \pm 0.6$ & $16.7 \pm 1.1^{\#}$ & \# baseline : others $p<0.001$ \\
\hline Vitamin C & I & $129 \pm 50$ & $164 \pm 64$ & $126 \pm 53$ & $182 \pm 49$ & ns \\
\hline$(\mathrm{mg} / \mathrm{d})$ & II & $121 \pm 43$ & $62 \pm 11$ & $132 \pm 40$ & $167 \pm 65$ & \\
\hline $\mathrm{Ca} / \mathrm{Fe}$ ratio & I & $95.7 \pm 25.0^{\mathrm{b}, \mathrm{c}}$ & $74.1 \pm 24.2^{\mathrm{a}}$ & $45.7 \pm 6.6^{\mathrm{a}, \mathrm{c}}$ & $54.2 \pm 7.1^{\mathrm{b}}$ & ${ }^{\mathrm{a}} p<0.05,{ }^{\mathrm{b}} p<0.01,{ }^{\mathrm{c}} p<0.001$ \\
\hline$(\%)$ & II & $87.5 \pm 23.8^{a, b, c}$ & $59.2 \pm 15.4^{\mathrm{a}}$ & $39.7 \pm 6.2^{c}$ & $52.7 \pm 2.6^{\mathrm{b}}$ & ${ }^{\mathrm{a}} p<0.05,{ }^{\mathrm{b}} p<0.01,{ }^{\mathrm{c}} p<0.001$ \\
\hline $\mathrm{Ca} / \mathrm{P}$ ratio & $\mathrm{I}$ & $0.61 \pm 0.11$ & $0.79 \pm 0.07$ & $0.82 \pm 0.08$ & $0.88 \pm 0.08^{\#}$ & ${ }^{\#}$ baseline : others $p<0.001$ \\
\hline$(\%)$ & II & $0.58 \pm 0.08$ & $0.85 \pm 0.09$ & $0.73 \pm 0.09$ & $0.83 \pm 0.05^{\#}$ & ${ }^{\#}$ baseline : others $p<0.001$ \\
\hline Vit $\mathrm{C} / \mathrm{Fe}$ ratio & I & $24.3 \pm 17.1$ & $19.8 \pm 19.2$ & $9.6 \pm 9.1$ & $11.9 \pm 7.7$ & \\
\hline$(\%)$ & II & $22.2 \pm 11.1^{\mathrm{a}, \mathrm{b}, \mathrm{c}}$ & $4.1 \pm 1.3^{\mathrm{c}}$ & $7.2 \pm 2.4^{b}$ & $9.8 \pm 4.8^{\mathrm{a}}$ & ${ }^{\mathrm{a}} p<0.05,{ }^{\mathrm{b}} p<0.01,{ }^{\mathrm{c}} p<0.001$ \\
\hline
\end{tabular}

I, simultaneous intake with milk during a meal; II, intake of milk between meals.

a,b,c Statistical difference was observed between the same initials within the same group. ns: No significant difference was observed between the groups or the times by ANOVA.

milk with iron supplementation during breakfast and dinner for 3 mo prevented iron loss in female collegiate athletes as compared to milk intake between meals. Further, milk intake during meals enhanced body iron stores as judged by the increased serum ferritin level (Table 2).

During this study, the physical activity level of the subjects increased from 1.83 (units) (baseline) to 2.26 (units) over a 3-mo period (subjects were evaluated using the RDA physical activity standard). Similarly, the estimated energy expenditure per day also changed from $2,093 \mathrm{kcal} / \mathrm{d}$ (baseline) to $2,121 \mathrm{kcal} / \mathrm{d}(1 \mathrm{mo})$, $2,233 \mathrm{kcal} / \mathrm{d}(2 \mathrm{mo})$ and $2,493 \mathrm{kcal} / \mathrm{d}$ when the study concluded $(3 \mathrm{mo})$. All subjects maintained their usual athletic training throughout the study and showed a body fat decrease of approximately $2 \%$.

There is abundant evidence that some biochemical components of a meal influence non-heme iron absorption. Phytate, tannin and some types of dietary fiber inhibit iron absorption in the small intestine. On the other hand, ascorbic acid is widely believed to enhance iron absorption. Other components including unknown ones found in food also may have some inhibitory or enhanced effect on intestinal iron absorption.

Previous observations of the effect of oral calcium intake on iron absorption are inconsistent. Although oral calcium intake interferes with iron absorption at the intestinal level (18-20), neither enhanced nor inhibited effects on iron absorption resulting from the ingestion of milk has been reported $(21,22)$. Barton et al. $(20)$, using electron microscopical observations and quantitative studies of the mucosal uptake and transfer of iron, indicated that calcium reduced the entry of iron to the microvilli of intestinal epithelial cells in rats. From that observation, they concluded that individuals consuming a high-calcium diet containing marginal amounts of iron could develop iron-deficient anemia, which might explain why infants who are fed cow's milk have a greater incidence of iron-deficient anemia than those fed human milk.

Tidehag et al. (21) determined whether or not milk, with its high calcium content, adversely affected the absorption of non-heme iron from single-meal studies, and estimated the apparent iron absorption (balance) and plasma ferritin concentration with ileostomy subjects. Their results indicated no decrease in apparent iron absorption during milk-diet periods. Furthermore, Turnlund et al. (22) studied the availability of iron from cereal-based diets with and without milk by use of ${ }^{54} \mathrm{Fe}$. They reported that in vivo and in vitro effects may differ, and that the absorption of iron from cereal-based diets is neither enhanced nor inhibited by the addition of milk. Gleerup et al. (16) compared the duration of the inhibitory effect on non-heme iron absorption of calcium $(340 \mathrm{mg})$ from milk and cheese in a breakfast meal to a hamburger meal at 2 or $4 \mathrm{~h}$ after breakfast, and found no durational effect of calcium on iron absorption. This strongly suggests that the inhibitory effect of calcium on iron absorption might be of short duration (16). Since these results were obtained from sin- 
gle meals, observations might not reflect habitual effects. In studies on the relationship between iron absorption and iron status, it is advantageous to estimate absorption not just from a single meal, but from the whole diet over a period of time (23).

Ohta et al. (24) reported that fluctooligosaccharides (FO) improved recovery from anemia. FO intake increased the $\mathrm{Ht}$ ratio, $\mathrm{Hb}$ concentration and $\mathrm{Hb}$ regeneration efficiency during the first week, and increased the absorption of iron in iron-deficient rats. Hallberg (25) reported that the percentage of iron absorption from complex meals ranged from $2.2-45.0 \%$ depending on the content of meat, ascorbic acid, organic acids, bran and other substances. Cook et al. (26) also investigated the effect of diets on dietary non-heme iron absorption estimated by serum ferritin concentrations, and reported no significant difference in dietary absorption between the subjects that consumed their usual diet $(6.4 \%)$ and those who followed diets to promote iron maximum absorption (8.0\%). This suggests that nonheme iron bioavailability is unchanged under various dietary conditions. The results obtained from serum ferritin concentrations indicate ferritin measurements may be important for assessing a precise nutritional condition at the whole body level. The results of Turnlund et al. (22) suggest that the absorption of iron from cereal-based diets is neither enhanced nor inhibited by the addition of milk. This observation is consistent with our results that serum ferritin concentrations were not decreased in group I, but rather enhanced with the addition of milk at 3 mo after dietary intervention.

We investigated body iron stores to estimate body iron bioavailability by varying the timing of milk intake for 3 mo. Female athletes, especially those participating in rhythmic gymnastics, are particularly prone to iron deficiency and iron-deficient anemia. A long duration of vigorous physical exercise may be associated with iron absorption disorders and an increased loss of iron in sweat, feces and urine $(27,28)$.

An important finding in this study is that the representative athletic diets taken by our subjects, especially during weight loss periods, were nearly optimal with respect to preventing anemia because the diets involved $50-60 \mathrm{~g}$ of protein and $16-18 \mathrm{mg}$ of iron per day throughout the study period. Female athletes who ingested milk simultaneously with iron-supplemented meals twice a day for 3 mo had enhanced body iron stores compared to the athletes who had milk between meals. The intake of energy, protein, carbohydrates, calcium, iron and vitamin $\mathrm{C}$ were similar for the two groups. The ratio of dietary calcium to iron intake decreased significantly in both groups (Table 3 ), and the value almost reached the recommended daily allowance in Japan (29). Although the ratio of dietary vitamin C-to-iron intake decreased significantly in group II after the start of the study, the ratio of dietary vitamin C-to-iron intake in group I remained unchanged throughout the study. These observations suggest that the ratio of dietary vitamin C-to-iron intake do not al- ways affect serum ferritin levels.

Pallares et al. (30) studied the influence of a commercial cereal-milk formula with bovine blood on iron, calcium, phosphorus and magnesium metabolism in control and iron-deficient rats, and found that when the iron content of the cereal-milk formula was doubled by supplementation with bovine blood, the overall iron status improved in the iron-deficient rats. Under our experimental conditions, it seems likely that the increased intake of iron (16-18 mg) also enhanced iron stores effectively.

Although the total intake of protein did not change throughout the study, calcium and iron intake increased significantly 3 mo after the start of this study. Furthermore, meals with milk did not affect some nutrient intake during the study, but athletes who had meals without milk showed some changes in daily nutrient intake as a result of skipping meals.

Based on these results, we conclude that iron-fortified meals with milk do not affect body iron stores, but improved nutrient intake results from maintaining regular meal times and frequency.

\section{Acknowledgments}

Iron pyrophosphate (Zavas Fe TAB) was kindly provided by Meiji Seika Kaisha Ltd., Japan. This study was supported by a grant from the Japan Amateur Sports Association in 1998. We wish to acknowledge their help.

\section{REFERENCES}

1) Tuntawiroon M, Stritongkul N, Brune S, RossanderHulten L, Pleehachinda R, Suwanik R, Hallberg L. 1991. Dose-dependent inhibitory effect of phenolic compounds in foods on non-heme iron absorption in men. Am J Clin Nutr 53: 554-557.

2) Cook JD, Reddy MB, Burri J, Juillerat MA, Hurrell RF. 1997. The influence of different cereal grains on iron absorption from infant cereal foods. Am J Clin Nutr $\mathbf{6 5}$ : 964-969.

3) Schmid A, Jakob E, Berg A, Russmann T, König D, Irmer M, Keul J. 1996. Effect of physical exercise and vitamin C on absorption of ferric sodium citrate. Med Sci Sports Exerc 28: 1470-1473.

4) Davidsson L, Walczyk T, Zavaleta N, Hurrell RF. 2001. Improving iron absorption from a Peruvian school breakfast meal by adding ascorbic acid or $\mathrm{Na}_{2}$ EDTA. Am J Clin Nutr 73: 283-287.

5) Davidsson L, Walczyk T, Morris A, Hurrell RF. 1998. Influence of ascorbic acid on iron absorption from an iron-fortified chocolate-flavored drink in Jamaican children. Am J Clin Nutr 67: 873-877.

6) Stekel A, Olivares M, Pizarro F, Chadud P, Lopez I, Amar M. 1986. Absorption of fortification iron from milk formulas in infants. Am J Clin Nutr 43: 917-922.

7) Cupisti A, D'Alessandro C, Castrogiovanni S, Barale A, Morelli E. 2000. Nutrition survey in elite rhythmic gymnasts. J Sports Med Phys Fitness 40: 350-355.

8) Dueck CA, Manore M, Matt KS. 1996. Role of energy balance in athletic menstrual dysfunction. Int J Sport Nutr 6: 165-190.

9) Wakui A, Shimomitsu T, Odagiri Y, Ohya Y, Katsumura T. 1999. Eating disorder symptoms, weight loss behav- 
iors and weight-cycling in female college students: correlates of exercise practice. Jpn J Phys Fitness Sports Med 48: $607-618$.

10) Dueck CA, Matt KS, Manore MM, Skinner JS. 1996. Treatment of athletic amenorrhea with a diet and training intervention program. Int J Sport Nutr 6: 24 40.

11) Eichner ER. 1992. Sports anemia, iron supplements, and blood doping. Med Sci Sports Exerc 24: S315-S318.

12) Willis WT, Gohil K, Brooks GA, Dallman PR. 1990. Iron deficiency: Improved exercise performance within 15 hours of iron treatment in rats. J Nutr 120: 909-916.

13) Bronner F, Stein WD. 1995. Chapter 5. Calcium nutrition and osteoporosis. In: Nutrition and Health: Topics and Controversies, p 113-135. CRC Press, New York.

14) Ministry of Health, Labour and Welfare. 2001. Report of the National Nutritional Survey in Japan.

15) Hallberg L, Rossander-Hulten L, Brune M, Gleerup A. 1992. Calcium and iron absorption: mechanism of action and nutritional importance. Eur J Clin Nutr 46: 317-327.

16) Gleerup A, Rossander-Hulten L, Hallberg L. 1993. Duration of the inhibitory effect of calcium on nonhaem iron absorption in man. Eur J Clin Nutr 47: 875879.

17) The Science and Technology Agency of Japan. 1998. Standard Tables of Food Composition in Japan (4th). Hitotsubashi Shuppan, Tokyo.

18) Hallberg L, Rossander-Hulten L, Brune M, Gleerup A. 1992. Calcium and iron absorption: mechanism of action and nutritional importance. Eur J Clin Nutr 46: 317-327.

19) Hallberg L, Brune M, Erlandsson M, Sandberg AS, Rossander-Hulten L. 1991. Calcium: effects of different amounts on nonheme- and heme-iron absorption in humans. Am J Clin Nutr 53: 112-119.

20) Barton J, Conrad ME, Parmley RT. 1983. Calcium inhibition of inorganic iron absorption in rats. Gastroenterology 84: 90-101.
21) Tidehag P, Sandberg AS, Hallmans G, Wing K, Turk M, Holm S, Grahn E. 1995. Effect of milk and fermented milk on iron absorption in ileostomy subjects. Am J Clin Nutr 62: 1234-1238.

22) Turnlund JR, Smith RG, Kretsch MJ, Keyes WR, Shah AG. 1990. Milk's effect on the bioavailability of iron from cereal-based diets in young women by use of in vitro and in vivo methods. Am J Clin Nutr 52: 373378.

23) Hallberg L, Hulten L, Gramatkovski E. 1997. Iron absorption from the whole diet in men: how effective is the regulation of iron absorption? Am J Clin Nutr 66: 347-356.

24) Ohta A, Ohtsuki M, Baba S, Takizawa T, Adachi T, Kimura S. 1995. Effects of fructooligosaccharides on the absorption of iron, calcium and magnesium in irondeficient anemic rats. $J$ Nutr Sci Vitaminol 41: 281291.

25) Hallberg L. 1981. Bioavailability of dietary iron in man. Annu Rev Nutr 1: 123-147.

26) Cook JD, Dassenko SA, Lynch SR. 1991. Assessment of the role of nonheme-iron availability in iron balance. Am J Clin Nutr 54: 717-722.

27) Yoshimura H, Inoue T, Yamada T, Shiraki K. 1980. Anemia during hard physical training (sports anemia) and its causal mechanism with special reference to protein nutrition. Wld Rev Diet 35: 1-86.

28) Beard J, Tobin B. 2000. Iron status and exercise. Am J Clin Nutr 72: 594s-597s.

29) Kenkou - Eiyou Johou Kenkyukai. 1998. 6th Edition of Recommended Dietary Allowance for Japanese, Dietary Reference Intakes, Daiichi-Shuppan, Tokyo.

30) Pallares I, Campos MS, Lopez-Aliaga I, Barrionuevo M, Gomez-Ayala AE, Alferez MJ, Hartiti S, Lisbona F. 1996. Supplementation of a cereal-milk formula with haem iron palliates the adverse effects of iron deficiency on calcium and magnesium metabolism in rats. Ann Nutr Metab 40: 81-90. 